\title{
Application of Hybrid Finite/Discrete Element Modelling for Back- Analysis of Rock Slope Failure Mechanisms
}

\author{
J.S. Coggan Camborne School of Mines, University of Exeter, United Kingdom \\ R.J. Pine Camborne School of Mines, University of Exeter, United Kingdom \\ T.D. Styles Camborne School of Mines, University of Exeter, United Kingdom \\ D. Stead Department of Earth Sciences, Simon Fraser University, Canada
}

\begin{abstract}
Slope stability in fractured rock masses is of fundamental importance across a wide spectrum of applications including landslides in coastal and hill areas, most rock quarry excavations, large scale open pits and civil engineering projects for transportation corridors (principally road and rail). Numerical modelling, when used appropriately, can be used to provide insight into potential failure mechanisms and assist the slope design process. Back-analysis of previous slope instability provides valuable information regarding the failure mechanism and, importantly, can provide valuable data for future design. A review of the results from both previous and more recent modelling of the back-analysis of the 1967 failure of the West face at Delabole Slate Quarry is used to provide the framework for evaluation of the application and benefits of potential methods of slope stability analysis. This includes the results from more recent modelling using a hybrid finite/discrete element modelling approach to model complex rock slope failure, including fracture extension, progressive step-path failure and brittle fracture propagation.
\end{abstract}

\section{Introduction}

As surface excavations become more extensive and increasingly deep realistic modelling of large slope behaviour is of critical importance for slope design. Stead et al. (2006) provided a review of recent advances/developments in the characterisation of complex rock slope failure. This included a review of the critical input parameters, advantages and limitations of conventional methods of analysis (such as stereographic, kinematic, limit equilibrium and rockfall), continuum and discontinuum numerical modelling approaches to simulate rock mass behaviour and hybrid methods of analysis. They introduced different levels of analysis, reproduced in Figure 1, to emphasise the application of these different techniques/approaches to increasing complexity of the associated slope failure mechanism. Eberhardt et al. (2004) also demonstrated the capabilities of these different modelling approaches for improved understanding of the Randa rockslide. The analysis included investigation of underlying mechanisms contributing to the episodic nature of the rockslide. Other examples of the use of numerical modelling to investigate slope failure mechanisms from recent literature include Board et al. (1996), Corkum and Martin (2002), Hencher et al. (1996), Hutchinson et al. (2000) and Stacey et al. (2003). To successfully simulate or back-analyse slope failure numerical models must not only capture the key aspects of fractured rock mass behaviour but they should also be representative of the scale and geometry.

This paper explores the potential use of numerical modelling for slope stability analysis through a review of the results from modelling of the back-analysis of the 1967 failure of the West face at Delabole Slate Quarry. Coggan and Pine (1996), using UDEC (Itasca, 1992) successfully simulated the complex interaction between discrete blocks making up the simplified failure geometry; including sliding, toppling and block rotation promoted by downward movement of chisel-shaped blocks. Modelling of the failure using the hybrid finite/discrete element software ELFEN (Rockfield Software, 2007), summarised by Coggan et al. (2003), was able to successfully capture progressive fracturing within the central section of the slope and the subsequent fragmentation and transport of the failed rock mass. More recent ELFEN modelling of the failure has concentrated on simulation of the effects of a pre-defined fracture or discontinuity network where critical discontinuities have more limited persistence. The results show regions of progressive brittle fracture and 
highlight the need for fracture extension and intact rock failure to allow kinematic release and subsequent failure of the modelled slope. The case example is used to highlight the current status of the hybrid modelling approach applied to back-analysis of slope failure mechanisms, including a summary of the key benefits and limitations.

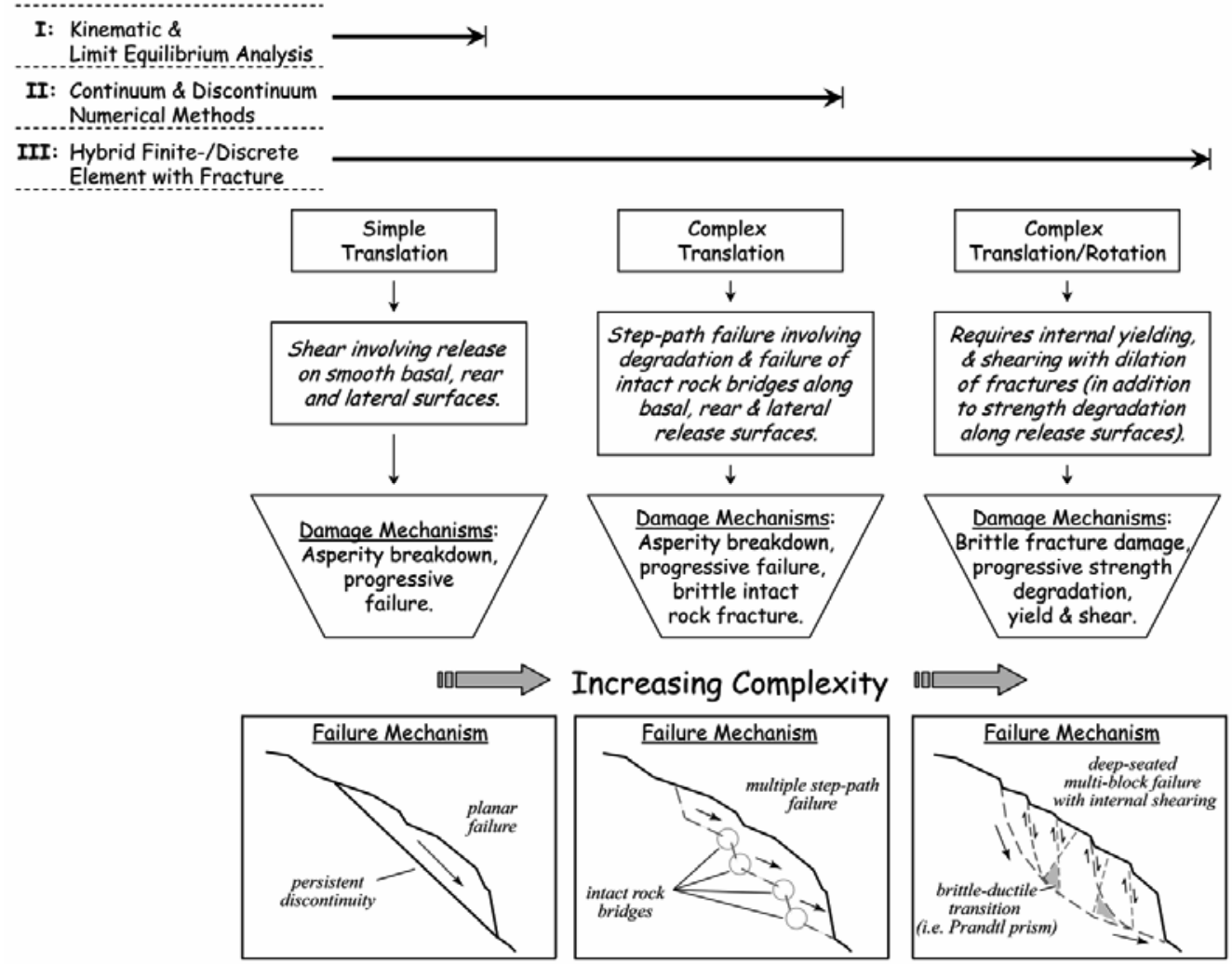

Figure 1 Diagram illustrating three levels of slope instability analysis and the associated increasing complexity of the modelled failure mechanism (after Stead et al., 2006)

\section{Key aspects of the 1967 Delabole failure}

High-quality slate has been quarried at Delabole Slate quarry, north Cornwall, for several centuries. The West face has a history of instability including a failure in 1967. Coggan and Pine (1996) provide a summary of the previous geotechnical investigations undertaken at the quarry; key aspects of which are highlighted below. Figure 2 shows the current profile of slope face taken from the haul road at the crest of the East face. Monitoring of tension-crack deformation, which was instigated by the quarry's management in 1948, was used to predict the 1967 failure and signal the need for appropriate action. Continued use of tension-crack monitoring and remote electronic distance measurement (EDM) between fixed base stations and strategic targets has shown further non-accelerating deformation.

Coggan and Pine (1996) provided details of the controlling influence of the major discontinuities on quarrying operations. Figure 3 shows a lower-hemisphere stereographic pole plot of the identified sets together with their local names. The shear-strength characteristics of several of these discontinuities have been summarised by Brown and co-workers (Brown et al., 1977).

Several possible mechanisms have been suggested for the 1967 failure that affected a number of benches and extended approximately $50 \mathrm{~m}$ along strike. All involve the interaction of several distinct blocks of rock and suggest a progressive multi-block failure mechanism with a component of block rotation and translation. Figure 4 shows the simplified pre-failure geometry suggested by Clover (1978) and a recent image of the post-failure scar. The major discontinuities that were thought to influence the failure were the shortahs (faulting), claylodes (faulting), cleavage, grain (secondary cleavage) and ratchels (faulting). The failure has been previously analysed using several different approaches. For example, Clover (1978) simplified the failure surface and applied various analytical techniques, including Limit Equilibrium analysis using Janbu's 
method of slices. The same simplified surface was also analysed using the Sarma method and an activepassive wedge approach. Back-analysis of the failure, summarised by Brown (1984), suggested that failure involved the interaction of four major blocks with sides defined by the face, the claylodes and the failure surfaces as shown schematically in Figure 4a. Downward movement of the chisel-shaped blocks 1 and 2 could induce rotation of block 3 which could in turn cause block 4 to slip on the lower section of the failure surface.

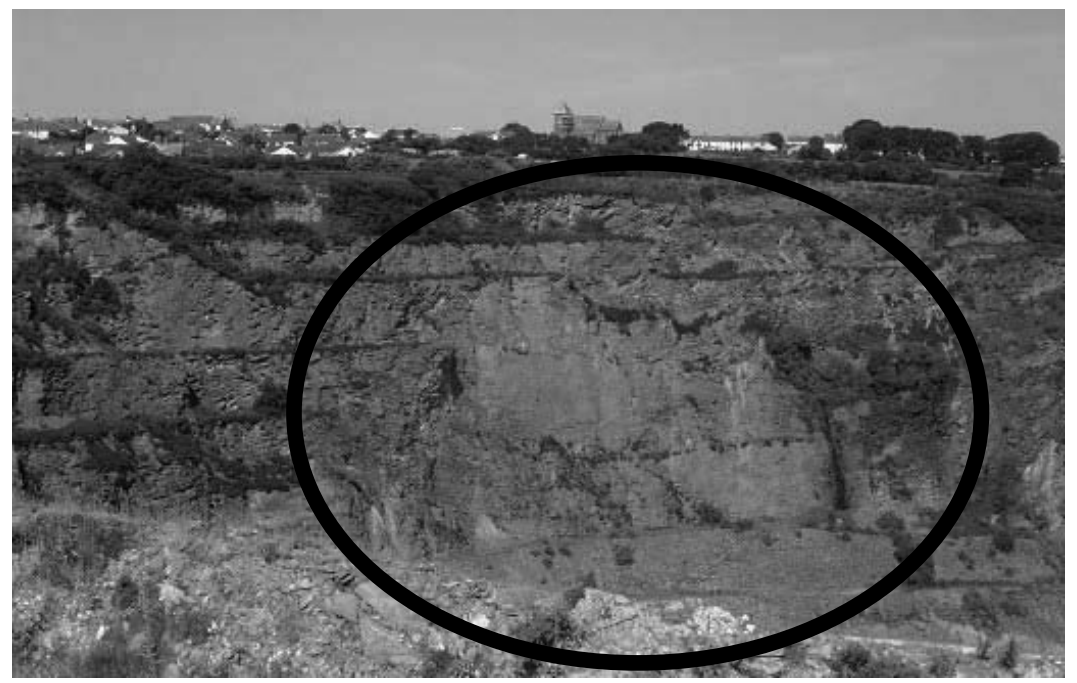

Figure 2 Current profile of the West face, Delabole Slate quarry taken from the haul road at the crest of the East face looking west with the 1967 failure highlighted

\section{Numerical modelling of the 1967 failure}

The approach utilised during modelling of the 1967 failure is based on guidelines from Starfield and Cundall (1988), where the modelling was performed to promote understanding of mechanisms rather than provide a detailed analysis. Recent developments in both hardware and software over the last decade have allowed further insight into the possible mechanisms. Increased computer power has resulted in reduced run times and, more importantly, software development has provided an ability to realistically model brittle failure, including extension of pre-defined fractures and development of new fractures through failure of previously intact rock bridges. Initial analyses concentrated on simulation of the rock-block interaction and modelled the slope geometry as being in-place before the analyses started. Later models included simulation of the excavation history but this did not have a significant influence on the modelled results.

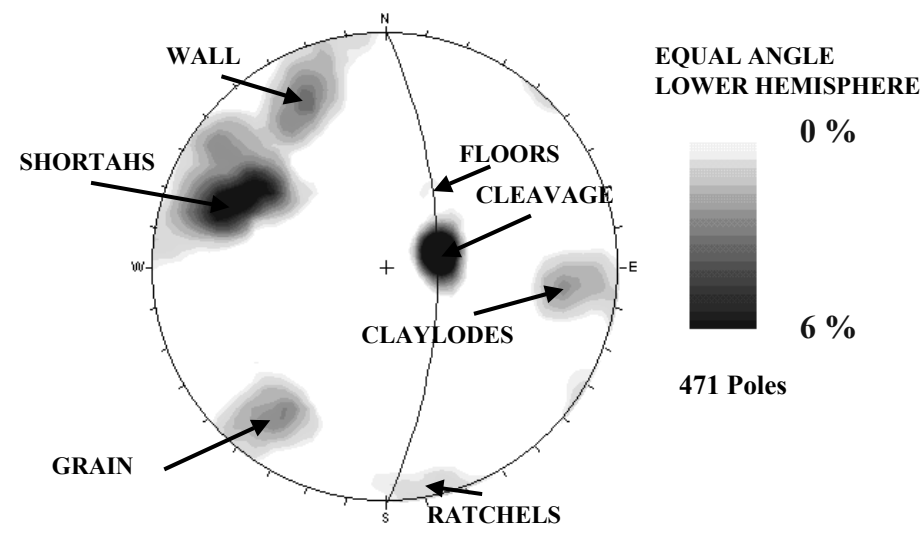

Figure 3 Lower hemisphere pole representation of the measured discontinuity sets. Great circle represents the West face 

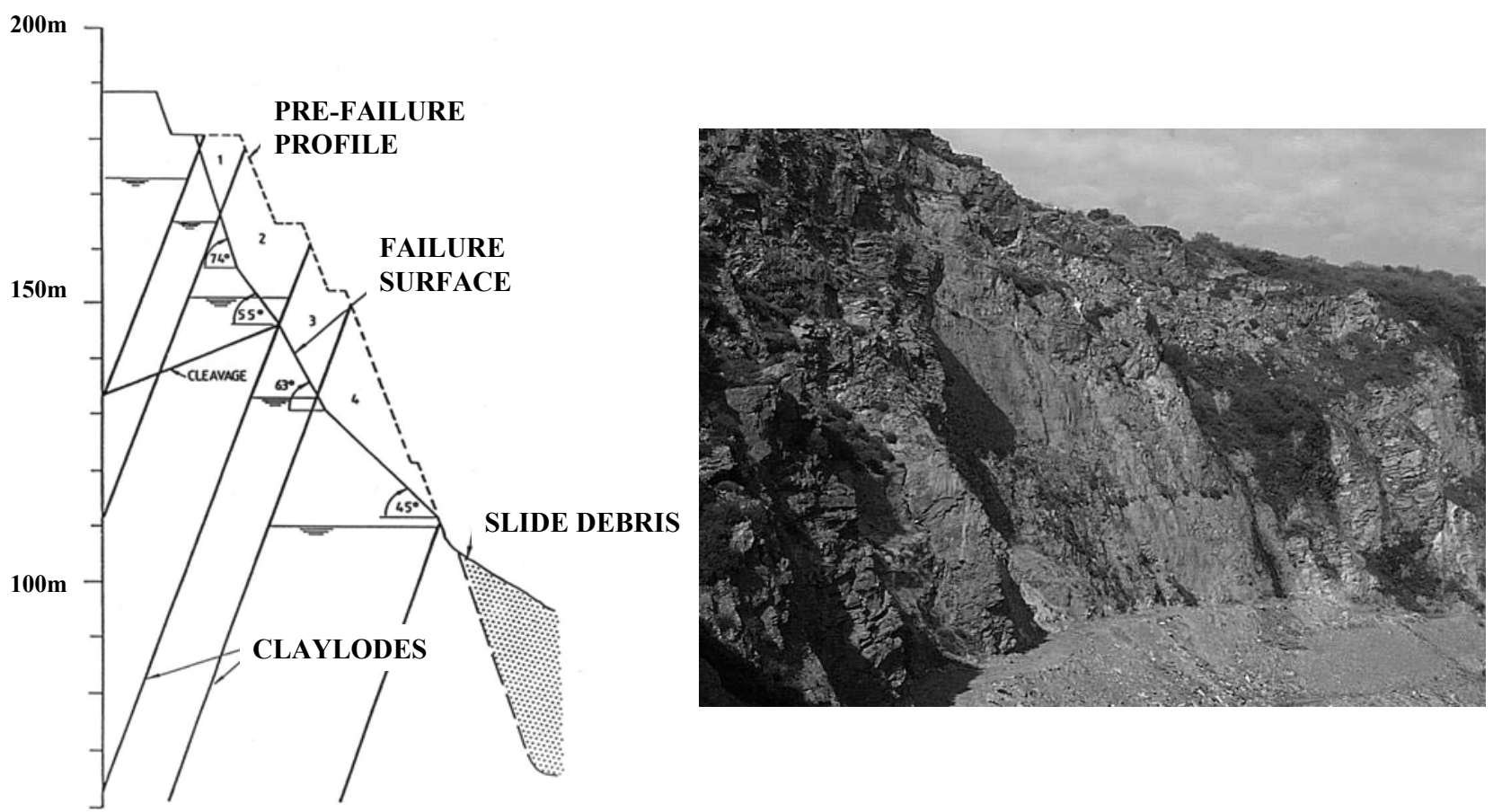

Figure 4 Images of the 1967 slope failure, showing a) cross-section, looking towards North, of the simplified failure geometry suggested by Clover (1978) and b) the current failure scar

\subsection{Summary of previous discrete element modelling (Coggan and Pine, 1996)}

In view of the discontinuity-controlled nature of the 1967 failure Coggan and Pine (1996) successfully used a simplified distinct element modelling approach to demonstrate that the complex block interaction suggested by Brown (1984) was plausible. Only the persistent faulting was directly incorporated in the UDEC model. The modelling approach used a simple representation of the failure geometry with emphasis on the potential influence of major persistent discontinuities.

Figure 5 shows modelled displacement vectors and horizontal displacement contours in the vicinity of the 1967 failure. The results of the modelling suggested that deep-seated flexural toppling on the claylodes may also contribute to the failure process and instability of the slope. The modelling also suggested that a perched or raised water table could have a detrimental effect on slope stability, and the observed cyclic opening and closing of the tension cracks could be related to the rise and fall of the water table in the annual cycle.

\subsection{Summary of initial hybrid finite/discrete-element modelling}

Early use of the hybrid finite/discrete element code ELFEN (Rockfield Software, 2007) to model the 1967 failure, summarised in Coggan et al. (2003) and shown in Figure 6, also treated the rock fracture network as a series of continuous discontinuities. These relatively simple models provided a useful insight into rockblock interaction, brittle fracture processes and resulting failure mechanisms. They also provided early examples of a 'total slope failure' analysis suggested by Stead and Coggan (2006), where selected stages in the hybrid finite/discrete-element simulation are used to highlight the fracturing within the central section of the rock slope associated with initiation of toppling and sliding movements followed by fragmentation of the slatey rock mass during post failure transport. 

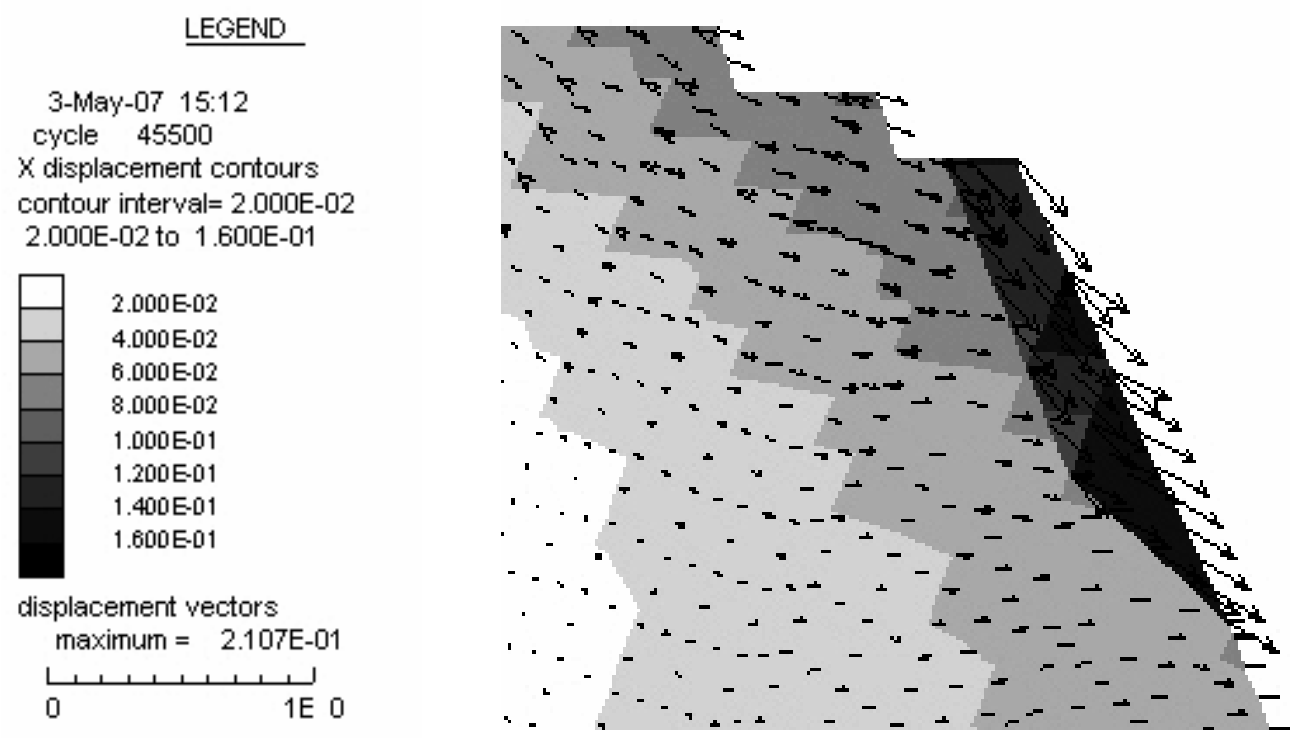

Figure 5 Modelled displacement vectors and horizontal displacement contours, using UDEC, showing deformation of the 1967 failure geometry and flexural toppling on the steeply inclined claylodes

\subsection{Modelling of non-continuous pre-defined discontinuities}

The next stage in the modelling approach was to insert discrete non-persistent fractures into the modelled slope to evaluate the possible effects of fracture continuity on model behaviour. This stage of modelling within ELFEN represented the rock mass as a series of non-continuous features that require intact rock failure to generate the necessary kinematic release and subsequent failure of the modelled slope. Selected stages of the modelled failure, shown in Figure 7, highlight the initial fracture geometry and subsequent development through the extension of pre-existing discontinuities and development of new fractures. The results highlight the step-path nature of the modelled failure, together with internal fracturing and subsequent rotation and translation of the failed mass. Further modelling using varied fracture network configurations demonstrated that persistence of the basal plane had a controlling influence on fracture initiation, development and propagation, which in turn had a controlling influence on overall modelled slope instability.

The modelling also indicated that there is a need to provide sufficient detail within a model to adequately represent the fracture network and its associated engineering behaviour, and importantly, capture the key characteristics of the failure mechanism. Eberhardt et al. (2004) and Stead et al. (2006), when modelling the Randa rockslide, demonstrated how the adopted constitutive criterion or failure criterion could dictate and critically influence the modelled fracture development. It is important therefore to undertake sensitivity analyses on critical input parameters, and there is a need to include both discontinuity-controlled and material or rock mass-controlled failure. 

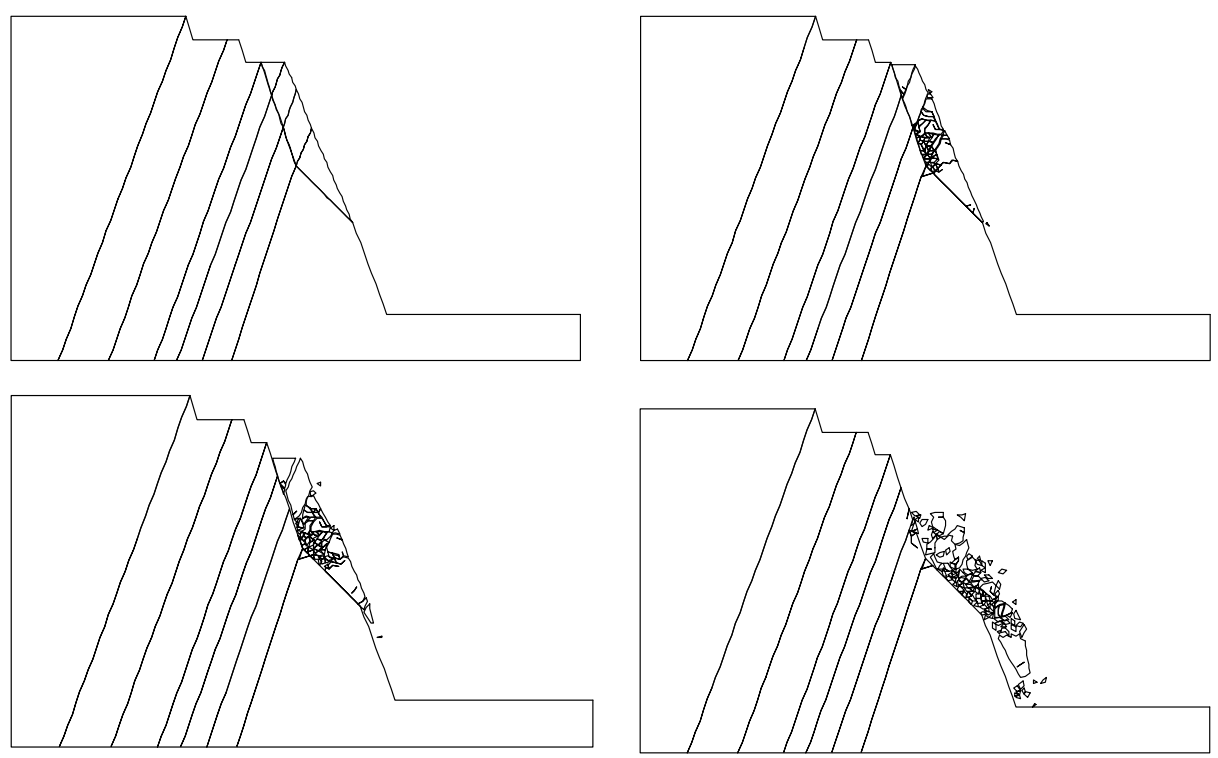

Figure 6 ELFEN 'total slope failure' analysis of the 1967 failure, showing the initial problem geometry and three stages of failure, passing from failure development through to runout
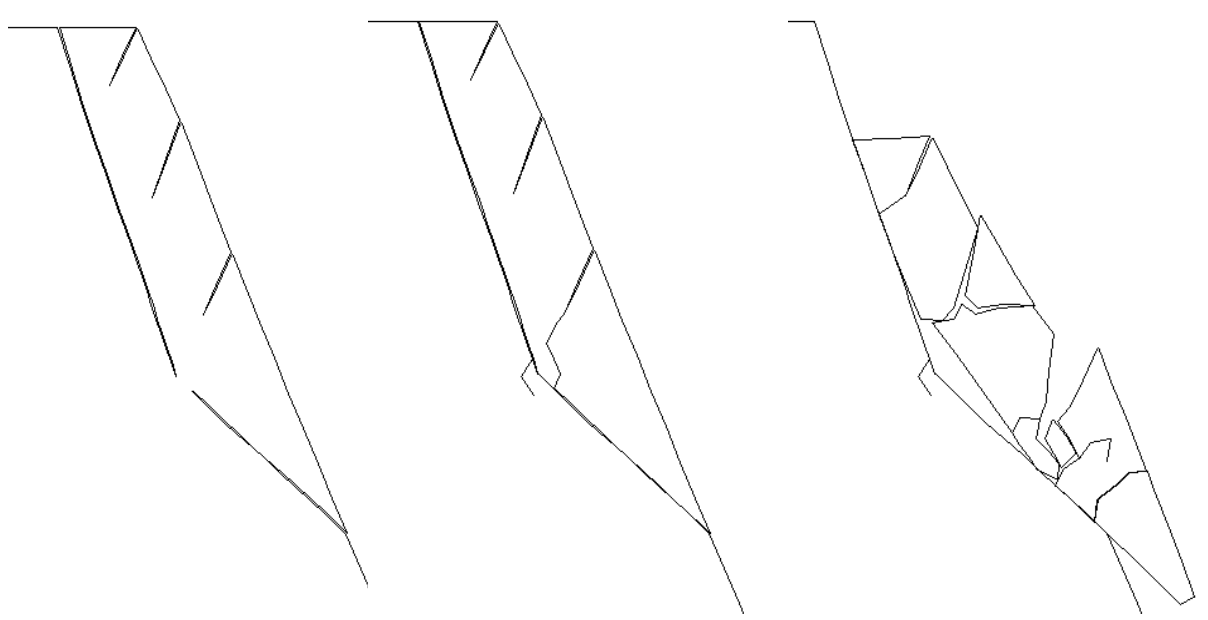

Figure 7 Modelled stages of the 1967 failure showing initial assumed fracture geometry and subsequent fracture development for non-continuous discontinuities

\subsection{Incorporation of a discrete fracture network to include the effects of more persistent claylodes}

In order to improve our understanding of the engineering behaviour of a blocky rock mass it is important to be able to simulate a more realistic fracture network within a modelled slope. Development of an interface between FracMan (Golder Associates, 2007), that provides the capability to generate 3D probabilistic fracture patterns from which 2D sections can be established, and ELFEN (Rockfield Software, 2007) as part of collaborative research between the Camborne School of Mines and the University of Swansea, described by Pine et al. (2006), now allows insertion of a more realistic discrete fracture network into modelled excavations. Although a major step forward, this in itself raises questions relating to what is a suitable or adequate representation of the fracture network geometry for a particular scale of slope or design problem. For this particular case study, where the overall slope height was greater than $100 \mathrm{~m}$, it was considered necessary to incorporate the effects of more persistent claylodes and assess the impact of various basal plane configurations on model behaviour. It was considered, however, that the overall fracture network should remain relatively simple to capture the key discontinuity behaviour. Figure 8 shows modelled stages of an 
example discrete fracture network where the block interaction, rotation and translation suggested by Brown are successfully captured. Figure 8 also shows a brittle fracture zone that develops between the high angle rear surface and the low angle basal plane. This is not dissimilar to the development of an internal damage zone or transition zone (Prandtl wedge) described by Mencl (1966) and Eberhardt et al. (2004) to explain failure along bi-linear slip surfaces.

It is possible to insert more sophisticated stochastic FracMan-generated fracture networks to represent the blocky rock mass, but this would result in increased mesh density and associated increase in run times to model the slope behaviour. In view of current software limitations groundwater related aspects of the failure were not considered in the two-dimensional modelling. The modelling philosophy adopted was to investigate the potential implications of brittle fracturing. There is an obvious trade-off between required model complexity, hardware requirements and associated run times; both should ultimately be balanced with available site knowledge and understanding, as suggested by Starfield and Cundall (1988). As with any numerical modelling approach there is a need to match software capability to hardware requirements. There is also a need to establish whether a two-dimensional analysis can effectively capture what is in reality a three-dimensional problem.
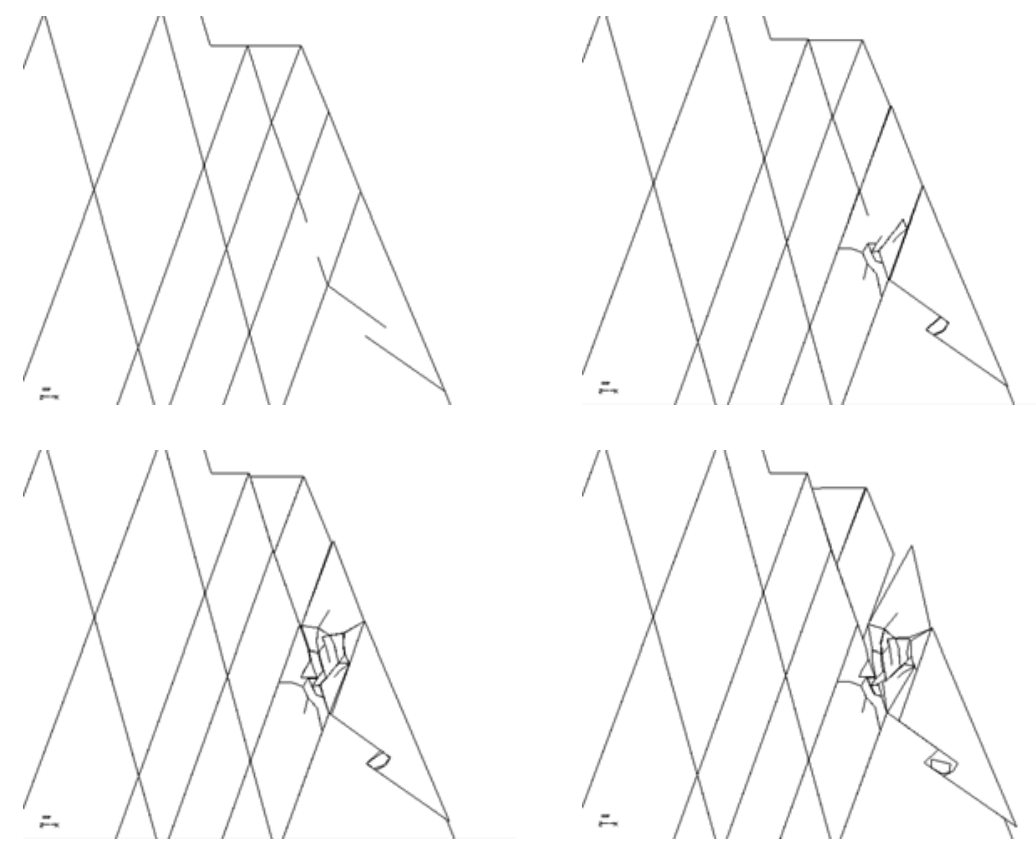

\section{Figure 8 Modelled stages showing fracture development including chisel effect, rotation and} subsequent translation of the failure geometry

\subsection{Simplified three-dimensional modelling of the 1967 failure}

With this in mind, but continuing the simplistic approach a pseudo three-dimensional analysis of the failure geometry was undertaken to demonstrate the three-dimensional capability of ELFEN. Figure 9 shows the pre-defined block geometry in the immediate vicinity of the failure and also highlights the driving action of the upper chisel-shaped block, the rotation and toppling of the adjacent block that in turn promotes translation on the lower failure surface. Images of the post failure scar shown in Figures 2 and $4 \mathrm{~b}$ suggest that the simple model shown in Figure 9 is an oversimplification due to blocky nature of the southern lateral release surface, but it demonstrates the potential to model internal fracture development in a limited 3D scale. Modelling of discrete fracture networks in large-scale slopes is problematic in both the 2D and 3D scenarios (e.g. Stead et al., 2007; Elmo et al., 2007) but, in the authors' opinion, with further developments in both hardware and software more representative three-dimensional models should be possible in the near future. 

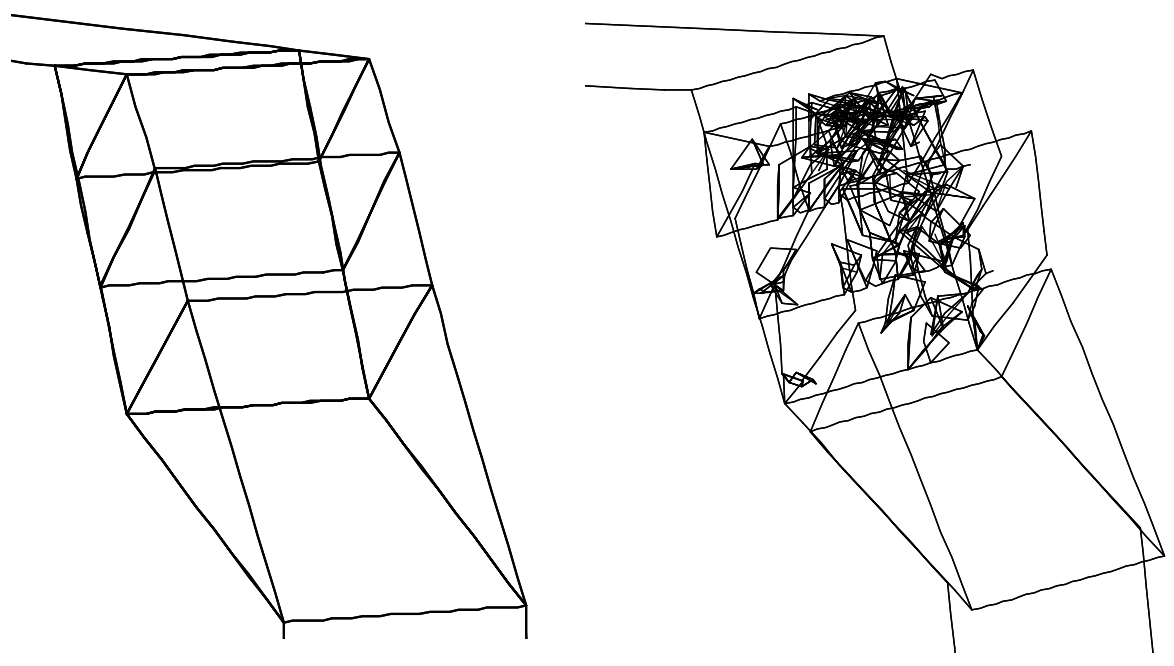

Figure 9 Simplified pseudo-three-dimensional model showing initial pre-existing fracture geometry in the vicinity of the 1967 failure and subsequent internal fracturing within the pre-defined failure geometry

\section{Back-analysis of the Delabole failure - techniques, advantages, limitations and future requirements}

The 1967 Delabole case example provides a good opportunity to review the application of discrete element numerical modelling techniques for back-analysis of discontinuity-controlled failure. The 1967 failure has been well documented, and the results of modelling undertaken with various methods of analysis can be compared. The key initial decision to make in any investigation is to determine the appropriate level of analysis (Figure 1). The method to adopt for the back-analysis depends on a number of factors and involves clear definition of the failure components and mechanisms. Ideally, the results of any back-analysis should be constrained against observations or monitoring data.

Stead et al. (2006) and Eberhardt et al. (2004) emphasised that it is often beneficial to undertake different methods of analysis in order to provide confidence in the results obtained from any one method. It is also important not to lose sight of why the back-analysis is being undertaken. For example, is it to promote understanding of factors controlling the failure, provide design data for future slopes or to provide predictions for future stability and minimise the potential for future instability?

Table 1, modified after Stead et al. (2006) provides a summary of the advantages and limitations of the various techniques used for back-analysis of the Delabole failure. The block interaction failure mechanism proposed by Brown has been successfully captured with both discrete element and hybrid modelling. Both models were able to model the deep seated flexural topple mechanism associated with more persistent claylodes. Discrete element modelling was also able to simulate the seasonal effects of groundwater, but the hybrid model was able to provide further insight into potential effects of a fracture network of more limited persistence. The results suggest that extension of pre-existing discontinuities or brittle failure of rock bridges could have contributed to the failure.

As previously indicated, back analysis of a slope failure can provide vital information for design purposes. The Delabole case example can be used to highlight the current status of numerical modelling applied to slope instability analysis, and provide implications for design of large slopes. Although the Delabole case example may be considered small to medium scale (approximately $100 \mathrm{~m}$ slope height) the adopted numerical modelling approach could be useful for future modelling of larger slopes that have complex/multiple failure mechanisms. Conventional design approaches based on either a Factor of Safety or probabilistic evaluation to assess the likelihood of slope failure can be complemented by numerical modelling of more complex behaviour. 
Table 1 Advantages and limitations of various techniques used for back-analysis of the 1967 Delabole slope failure (modified after Stead et al., 2006)

\begin{tabular}{|c|c|c|}
\hline Technique & Advantages & Limitations \\
\hline $\begin{array}{l}\text { Kinematic and } \\
\text { Stereographic }\end{array}$ & $\begin{array}{l}\text { Simple to use and show failure } \\
\text { potential. Can be used with statistical } \\
\text { techniques to indicate probability of } \\
\text { failure and associated volumes }\end{array}$ & $\begin{array}{l}\text { Suitable for preliminary design. } \\
\text { Identification of critical joints requires } \\
\text { engineering judgement. Must be used } \\
\text { with representative joint strength data }\end{array}$ \\
\hline $\begin{array}{l}\text { Limit } \\
\text { Equilibrium }\end{array}$ & $\begin{array}{l}\text { Software widely available for different } \\
\text { failure modes. Deterministic or } \\
\text { probabilistic analyses and groundwater } \\
\text { analysis. Suitable for sensitivity } \\
\text { analyses }\end{array}$ & $\begin{array}{l}\text { Factor of Safety calculations must } \\
\text { assume instability mechanisms. In-situ } \\
\text { stress, strains and intact material failure } \\
\text { not considered }\end{array}$ \\
\hline \multirow[t]{2}{*}{ Continuum } & $\begin{array}{l}\text { Allows for material deformation and } \\
\text { failure with coupled groundwater. Can } \\
\text { include shear strength reduction in both } \\
\text { 2D and 3D. Able to undertake } \\
\text { sensitivity analyses on input parameters. }\end{array}$ & $\begin{array}{l}\text { Considered to have limited application } \\
\text { to the modelling of the Delabole failure } \\
\text { in view of discontinuity-controlled } \\
\text { nature of the event and the need to } \\
\text { model rock block interaction }\end{array}$ \\
\hline & $\begin{array}{l}\text { Can include limited number of large } \\
\text { pre-existing structures }\end{array}$ & \\
\hline $\begin{array}{l}\text { Discontinuum } \\
\text { (UDEC) }\end{array}$ & $\begin{array}{l}\text { Allows for block deformation and } \\
\text { movement of blocks relative to each. } \\
\text { Can model complex behaviour and } \\
\text { mechanisms (combined material and } \\
\text { discontinuity behaviour, coupled with } \\
\text { hydro-mechanical analysis). Can } \\
\text { include shear strength reduction in both } \\
\text { 2D and 3D. Able to assess effects of } \\
\text { parameter variations on instability }\end{array}$ & $\begin{array}{l}\text { Need to simulate representative } \\
\text { discontinuity geometry (spacing, } \\
\text { persistence, etc.). Limited data on joint } \\
\text { properties available }\end{array}$ \\
\hline $\begin{array}{l}\text { Hybrid } \\
\text { finite/discrete- } \\
\text { element (ELFEN) }\end{array}$ & $\begin{array}{l}\text { Combines advantages of both } \\
\text { continuum and discontinuum methods. } \\
\text { Able to simulate intact rock fracture, } \\
\text { extension of existing fractures and } \\
\text { propagation of new fractures. Can } \\
\text { incorporate different constitutive } \\
\text { criterion. Able to insert discrete fracture } \\
\text { networks in both 2D and 3D. Able to } \\
\text { undertake sensitivity analyses on input } \\
\text { parameters }\end{array}$ & $\begin{array}{l}\text { Complex problems require high } \\
\text { memory capacity. Limited experience in } \\
\text { application to large slope problems. Yet } \\
\text { to be effectively coupled with } \\
\text { groundwater. Limited data available for } \\
\text { fracture mechanics properties, joint } \\
\text { contact properties and effects of scale. } \\
\text { Validation required through back- } \\
\text { analysis of case examples at different } \\
\text { scales (bench through to major slope } \\
\text { problems) and comparison of results } \\
\text { from other methods of analysis }\end{array}$ \\
\hline
\end{tabular}

The key role of numerical modelling is to provide evaluation and analysis of 'What if?' scenarios. However, when considering the choice of method of analysis depicted in both Figure 1 and Table 1 for large slopes it is important to be aware that the increase in modelling complexity can only bring about more value if accompanied with a greater understanding of the geotechnical conditions at the site i.e. each higher level in the modelling pecking order requires a better field investigation. Further research is therefore required to overcome some of the limitations, as indicated in Table 1, to modelling three-dimensional fracture networks at an appropriate scale for large slope analysis. The requirements include more efficient transfer of discrete fracture network input data, improved hardware to reduce run times and allow more representative models of large-scale slopes to be created and an improved understanding of the groundwater-mechanical-brittle interaction. 
Where possible, back-analysis should be performed using a variety of available software, both in two and three-dimensions, for validation purposes. The choice of software will ultimately depend on whether the rock mass is considered to behave as a continuum or discontinuum, but for complex failure mechanisms comparative modelling should be performed using hybrid methods that can capture the effects of discrete fracture networks and model rock fracture. In three-dimensions, future modelling should include comparative evaluation of such models as PFC3D/3DEC (Itacsa, 2007) and ELFEN to investigate the effects of lateral and rear release surface development and the influence of three-dimensional fracture networks on slope stability.

\section{Conclusions}

Back-analysis of slope failures can provide vital information for future design of slopes. The 1967 Delabole failure provides such an example where different methods of analysis can be used to provide improved understanding of slope failure mechanisms resulting from discrete fracture networks. Different methods of analysis were able to show that the failure most likely involved block rotation and translation, which was driven by a chisel-effect caused by down ward movement of the upper blocks. Deep-seated flexural toppling on persistent claylodes may also have influenced the failure. Discrete element modelling simulated the potential detrimental effects of a perched or raised water table and hybrid finite/discrete-element modelling suggested that fracture extension and brittle failure could have contributed to the overall failure process.

The case example highlights the potential application of the hybrid approach to modelling complex failure mechanisms that involve extension of an existing fracture network and brittle fracture of rock bridges. Further hardware and software developments are required, however, before we can realistically model threedimensional fracture networks at an appropriate scale for large slope analysis. Recent developments in monitoring, such as real-time deformation monitoring with radar technology and subsurface monitoring of internal slope deformation and microseismic activity may also be potentially very useful to constrain the modelling for back-analysis of slope failure.

\section{Acknowledgements}

The authors would like to thank the support of collaborators, including Professor Roger Owen of University of Wales, Swansea; Jon Rance of Rockfield Software Ltd and Steve Rogers of Golder Associates. The UK Engineering and Research Council (EPSRC) have provided support through research grants GR/S04970/1 and EP/C518713/1 (Exeter/CSM) and GR/S04987/1 and EP/C518721/1 (Swansea).

\section{References}

Board, M., Chacon, E., Varona, P. and Lorig, L. (1996) Comparative analysis of toppling behaviour at Chuquicamata open-pit mine, Chile. Inst. Min. Metall., Section A, 105, pp. A11-A21.

Brown, E.T. (1984) Stability of the western face, Delabole slate quarry. Report to Carnon Consolidated Tin Mines Ltd.

Brown, E.T., Richards, L.R. and Barr, M.V. (1977) Shear strength characteristics of the Delabole Slates. In Proc. Conf. on Rock Engineering. Attewell, P.B. (ed). Newcastle upon Tyne: The University, pp. 33-51.

Clover, A.W. (1978) Some aspects of the rock excavations on the western face at Delabole slate quarry, Cornwall. MSc dissertation, Imperial College, University of London, $99 \mathrm{p}$.

Coggan, J.S. and Pine, R.J. (1996) Application of distinct-element modelling to assess slope stability at Delabole slate quarry, Cornwall, England. Trans. Inst. Min. Metall. Section A, 105, pp. A22-A30.

Coggan, J.S., Pine, R.J., Stead, D. and Rance, J.M. (2003) Numerical modelling of brittle rock failure using a combined finite-discrete element approach: implications for rock engineering design. In ISRM 2003 - Technology roadmap for rock mechanics. S. Afr. Inst. Min. Metall. Symposium Series S33, Vol. 1, pp. 211-218.

Corkum, A.G. and Martin, C.D. (2002) Discrete element analysis of the effect of a toe berm on a large rock slide. In Proc. 55th Canadian geotechnical Conference, Niagara Falls. Canadian Geotechnical Society, Toronto, pp. 633640.

Eberhardt, E., Stead, D. and Coggan, J.S. (2004) Numerical analysis of initiation and progressive failure in natural rock slopes - the 1991 Randa rockslide. Int. J. Rock Mech. Min. Sci. 41 (1), pp. 69-87.

Elmo, D., Yan, M., Stead, D. and Rogers, S. (2007) The importance of intact rock bridges in the stability of high rock slopes: Towards a quantitative investigation using an integrated numerical modelling-discrete fracture network approach. In Proceedings of the International Symposium on Rock slope Stability in Open Pit Mining and Civil Engineering, Perth, Australia. 
Golder Associates (2007) FracMan Technology Group. www.fracman.golder.com

Hencher, S.R., Liao, Q.H. and Monaghan, B.G. (1996) Modelling slope behaviour for open-pits. Trans. Inst. Min. Metall. Section A, 105, pp. A37-A47.

Hutchinson, B., Dugan, K. and Coulthard, M.A. (2000) Analysis of flexural toppling at Australian bulk minerals Savage River mine. In Proc. GeoEng2000. Int. Conf. Geotech. Geol. Eng., Melbourne, CDROM, 6 p.

Itasca (1992) UDEC, Version 1.83 User's Manual. Itasca Consulting.

Itacsa (2007) PFC3D, 3DEC. Itasca Consulting. www.itascacg.com.

Mencl, V. (1966) Mechanics of landslides with non-circular slip surfaces with special reference to the Vaiont slide. Geotechnique; 16(4), pp. 329-337.

Pine, R.J., Coggan, J.S., Flynn, Z. and Elmo, D. (2006) The development of a comprehensive numerical modelling approach for pre-fractured rock masses. Rock Mechanics and Rock Engineering, 39, 5, pp. 395-419.

Rockfield Software Ltd (2007) ELFEN User Manual, Swansea, UK. www.rockfield.co.uk.

Stacey, T.R., Xianbin, Y., Armstrong, R. and Keyter, G.J. (2003) New slope stability considerations for deep open pit mines. J. S. Afr. Inst. Min. Metall., 103, pp. 373-389.

Starfield, J.L. and Cundall, P.A. (1988) Towards a methodology for rock mechanics modelling. Int. J. Rock Mech. Min. Sci. and Geomech. Abst., 25, pp. 99-106.

Stead, D. and Coggan, J.S. (2006) Numerical modelling of rock slopes using a total slope failure approach. In Landslide from Massive Rock Slope Failure, Evans, S., Hermans, R. and Strom, A. (eds), Springer, Dordrecht, Netherlands, pp. 131-142.

Stead, D., Eberhardt, E. and Coggan, J.S. (2006) Developments in the characterization of complex rock slope deformation and failure using numerical modelling techniques. Engineering Geology, 83, pp. 217-235.

Stead, D., Coggan, J.S., Elmo, D. and Yan, M. (2007) Modelling brittle fracture in rock slopes: Experiences gained and lessons learned. In Proceedings of the International Symposium on Rock Slope Stability in Open Pit Mining and Civil Engineering, Perth, Australia. 